\title{
RFM customer analysis for product-oriented services and service business development: an interventionist case study of two machinery manufacturers
}

\author{
Kati Stormi $^{1}$ (D) Anni Lindholm ${ }^{1} \cdot$ Teemu Laine $^{1} \cdot$ Tuomas Korhonen $^{1}$
}

Published online: 25 January 2019

(c) The Author(s) 2019

\begin{abstract}
This study examines how original equipment manufacturers (OEMs) can segment their product-oriented services customers with the help of a recency, frequency, and monetary value (RFM) analysis of service consumption. The study is an interventionist case study that uses two large OEMs as case companies, both seeking profitable growth in the area of services. The originality of the paper is threefold. First, the research extends the RFM analysis using four product-support-service-specific variables, and it outlines the similarities and differences between the industrial service and consumer business contexts when using the RFM analysis. Second, by applying and modifying the RFM model to better suit the product-support-service context, the study contributes to the literature on the governance of product-oriented services in manufacturing. Third, the paper contributes to the literature on management accounting supporting service business development, by introducing a method that can use installed base and customer information to measure, analyze and govern the business potential of an industrial machinery "fleet". In all, the paper is particularly helpful for service management and accounting academics and practitioners who wish to understand product-oriented service governance in environments in which there is a vast installed base of products at the customers, with remarkable potential for extending service business.
\end{abstract}

Keywords RFM analysis · Industrial services · Servitization · CRM $\cdot$ Customer segmentation

Kati Stormi

kati.stormi@gmail.com

Extended author information available on the last page of the article 


\section{Introduction}

There is emerging literature on creating revenue streams from after-sales services. Original equipment manufacturers (OEMs) especially can generate substantial revenues from a large installed base of products that have long life cycles (Gebauer et al. 2005). The after-sales function is a main strategic driver for ensuring long-term revenues and customer satisfaction (Cavalieri et al. 2007). Thus, it is necessary to produce supportive financial information for selecting and prioritizing the sales activities to support daily managerial work and govern these activities (Hall 2010). Exact knowledge of the installed base and its service requirements could indeed advance, for example, managing the offerings consisting of products and related product-oriented services, e.g., spare parts management (Wagner and Lindemann 2008) and end-user-oriented services such as training (Oliva and Kallenberg 2003; Ala-Risku 2009). According to another conceptualization, such knowledge could advance also services that aim to ensure functioning product life-cycle, support customers' processes, gain asset efficiency or even operate delegated shares of customers' processes (Ulaga and Reinartz 2011). In this paper, we will focus on services that fall into the category of spare parts and spare part management. Hence we will particularly focus on term "product-oriented services" (Oliva and Kallenberg 2003; Ala-Risku 2009) or "product life-cycle services" (Ulaga and Reinartz 2011). However, in this paper, we consider that Oliva and Kallenberg's (2003) definition best suits our vocabulary, and therefore we will use their term hereafter.

Capturing the value of the product-oriented services in the form of service revenues represents a challenge for manufacturing companies. In fact, many manufacturing companies that have offered their customers some supportive services "for free" aim at a business model transformation, in order to get revenues for their service activities (Witell and Löfgren 2013). Instead of a wide business model transformation, there is literature that suggest that there are plenty of different means for manufacturing companies, regarding costing, pricing and governing service activities in order to capture the value embedded and yield service revenues (Malleret 2006; Witell and Löfgren 2013). Building on these findings, this paper focuses on a tool that provides a better awareness of OEMs' existing product-oriented services, e.g., spare parts, and the related customer behavior. Such awareness could help OEMs manage their current product-oriented services and also find avenues for further developing their service offering.

More specifically, there is limited empirical evidence regarding how manufacturing companies plan, control and develop their service activities using management accounting information (Araujo and Spring 2006; Laine et al. 2012a). There are indications that management accounting practices that focus on spare parts business do not exist in many companies (Wagner and Lindemann 2008). In addition, manufacturing companies lack tools and techniques for steering their service business activities (Baines et al. 2009; Laine et al. 2012a), despite the potentials in using installed base information and other information sources for this purpose (see e.g., Ala-Risku 2009; Holmström et al. 2010; Saccani et al. 2012; 
Perminova-Harikoski et al. 2015). Creating supportive information for decision makers represents a challenge for many companies because information is scattered in different systems and forms (Lindholm et al. 2017). Quite understandably, prior research calls for new knowledge of how the provision of services drives change in financial information supply (Cinquini et al. 2015) and demand (Lindholm et al. 2017) in manufacturing industries. There is a need for integrative frameworks that help managers use information about their installed base, or their "machinery fleet", to govern the often global service networks. In this case, the machinery fleet can be described as the installed base that exist at an OEM's customers sites, and which offers a certain potential for after-sales service for the OEM. Importantly, although research points to advancements in measuring and managing the performance of service operations (e.g., Jääskeläinen et al. 2012; Pekkola et al. 2016), research does not yet adequately cover how managers can measure, analyze, and understand the service business potential of an industrial machinery fleet.

This paper offers a possible solution to the problem of acquiring knowledge and understanding about installed base service potentials and customers' service consumption behavior regarding product-oriented services. This solution is the recency, frequency, and monetary value (RFM) analysis. Originally, the RFM analysis evaluates customers based on $(R)$ how recent their latest purchase was, $(F)$ how frequently the customers have made purchases, and (M) how high the monetary value of their purchases has been. An RFM analysis is common in business-to-consumer (B2C) marketing (Verhoef et al. 2003). However, and somewhat surprisingly, examinations using an RFM analysis for managing and developing the product-oriented service business for the business-to-business (B2B) industries are lacking in the existing literature. Therefore, purposeful applications and possible needed modifications of the original RFM analysis are lacking. Indeed, the knowledge of the applicability of the RFM analysis to the industrial service context is not currently adequate, and requires further examination. There is enormous potential in combining installed base information into the customer segmentation analysis to understand which customers are particularly interesting for service sales and why this might be the case. For this reason, the objective of this paper is to examine the applicability and possibly supportive role of the RFM analysis in OEMs' product-oriented service sales and service business development.

The paper relies on qualitative inquiry, particularly on an interventionist case study (Jönsson and Lukka 2007; Lukka and Suomala 2014; Suomala et al. 2014; Laine et al. 2012b). A case study approach is a reasonable choice because the paper addresses a complex, longitudinal phenomenon, i.e., the governance of product-oriented services and embedded wider implications to the service business development. The case study focuses on two manufacturing companies that seek business growth in the area of services. The current paper pseudonymously presents these companies as FleetCo and ProcessCo. FleetCo manufactures mobile equipment, whereas ProcessCo manufactures stationary equipment. The choice of two cases is justified by the ability to unveil the dynamics of customer behavior and service business development in one manufacturing company case, and reflect upon the findings with another manufacturing company case. Both companies are large, and they 
have decades of experience from operating in their industries and providing productoriented services. These particular companies are a reasonable choice to inform the paper because although these companies have substantial product-oriented service activities, they have recognized their lacking capabilities in governing these activities. Besides, the companies are currently developing new types of service offerings. Their service offering development could be supported by an increased awareness of their customers' behavior regarding the service consumption. Although the case studies presented in this paper focus on spare parts sales as part of product-oriented service activities (Ala-Risku 2009; Ulaga and Reinartz 2011), the results of the paper can be applicable to other product-oriented services (such as maintenance) as well, and provide implications for developing service offerings more broadly in manufacturing - necessitating further research that is beyond this paper.

The contribution of the paper is threefold, and lies in the detailed examination of how OEMs can segment their spare parts and maintenance customers with the help of an RFM analysis. First, this paper presents the similarities and differences between the industrial service context and the consumer business context in using the RFM analysis. In particular, the paper shows that that the R, F, and M variables may have a different interpretation in B2B compared to B2C marketing. Hence, the paper contributes to the literature by applying the RFM analysis to the context of industrial services, especially regarding product-related services (Oliva and Kallenberg 2003; Ala-Risku 2009; Ulaga and Reinartz 2011). The results of this paper show that the RFM analysis can sort product-oriented service customers into meaningful segments. Firms can then focus service sales on these segments and hence effectively allocate service sales resources where they could be the most impactful. Furthermore, the study extends the RFM analysis with four variables: fleet size, part depth, part width, and altogether the fleet service business potential. These variables are potentially transferable across contexts outside product-related services as well. Second, by applying and modifying the RFM model to better suit the productsupport-service context, the paper contributes to the literature on the governance of product-oriented services in manufacturing (Oliva and Kallenberg 2003; Wagner and Lindemann 2008; Ala-Risku 2009; Baines et al. 2009; Ulaga and Reinartz 2011; Lindholm et al. 2017). The paper shows that RFM analyses (or similar approaches) could help managers identify different types of service customers and embedded service business potentials, and manage the customers according to their specific behavior. Third, more specifically, the paper contributes to literature on management accounting supporting service business development (Malleret 2006; Laine et al. 2012a; Lindholm et al. 2017) by introducing a method that can use installed base and customer information to measure, analyze and govern the business potential of an industrial machinery fleet. It is noteworthy that although the RFM analyses presented in this paper focus on the existing product-related services, information about the different customer segments regarding these service activities may provide insights into service potentials regarding more advanced services as well [see e.g., Laine et al. (2012b) for service business potential simulations]. The findings of this paper encourage further examinations from management accounting and governance perspectives. Overall, the paper encourages the servitization literature to find ways 
to utilize accounting information, especially information concerning the customers and the installed-base.

The paper is structured as follows: First, the paper looks at prior studies on profitability management in services and customer segmentation within customer relationship management (CRM). The paper especially covers studies that use the RFM analysis. Based on the literature, the paper builds a tentative framework. Then, a methodology section describes the data set and analysis methods. The empirical part complements the tentative framework using the results of the interventionist case studies at FleetCo and ProcessCo. Finally, the final section that contains the discussion and conclusions reflects on the empirical findings and prior literature and presents directions for further research.

\section{Theoretical background}

\subsection{Profitability management in services}

Service businesses challenge OEMs' management and governance structures and practices. Holmström et al. (2010) and Laine et al. (2012b) highlighted the importance of connecting the manufacturing companies' service activities to customers' value generations processes. The most profitable service activities may stem from the activities that are undertaken by the manufacturers in the most effective way according to the needs of the customers' processes. At the same time, despite the identification of the customers' value generation processes, and the creation of such value by means of new services provided by the OEMs, the profitability of those companies does not increase accordingly. Indeed, as examined by Malleret (2006) and Witell and Löfgren (2013), there are plenty of possibilities for manufacturing companies to provide value to their customers, but the business model and the governance are needed to ensure the actual revenue and cost effects to take place. For instance, as discussed by Witell and Löfgren (2013), some service activities may be considered traditionally as 'good service' for free by the customers, and this may hinder the profitability impacts of service business more broadly, despite the introduction of new service elements.

The different units of analysis and roles of financial information regarding manufacturing companies' service businesses have been discussed in the existing literature (Malleret 2006; Laine et al. 2012a). This is due to the fact that new service businesses require reconsideration of the existing governance and reporting structures-and even the contents of those activities. More particularly, because aftersales service businesses typically generate long-term revenue streams, managerial analyses and decision making should not focus only on per-transaction profitability (e.g., Cohen and Whang 1997), but on the wider value generation processes. Thus, in addition to product- and service-level analyses, the financial implication of service business actions need to be evaluated more broadly. For example, Laine et al. (2012a) point out that developing new service businesses may highlight the need to rethink the unit of analysis in management accounting, and that information 
regarding different units of analysis can be used for justifying, defining, and controlling the required or desired changes in those service businesses.

Particularly, many manufacturing companies aim at long-term customer relationships (e.g., Penttinen and Palmer 2007), and thus the nature of the new kinds of customer relationships needs to be more thoroughly captured by supporting management accounting analyses. It is noteworthy that, to a large extent, the long-term customer relationships tie OEMs' profitability to the profitability of their customers (Laine et al. 2012b). In this vein, Lindholm et al. (2017) suggest new performance indicators related to machinery fleets and their after-sales service needs (from the customer's viewpoint) and potentials (from the manufacturing company's perspective). Similarly, Korhonen et al. (2016) examine the possibilities to forecast customer behavior by using an extended understanding of the customers and their buying behavior. However, there is still a lot of potential in a better (and more proactive) understanding of the customers' service business needs and how these needs would best fit a manufacturing company's offerings (Anderson and Narus 2003).

Overall, developing new service businesses changes OEMs' profitability structures and thus their profitability management. Especially, there is a need for a better understanding about how OEMs can design and use some potential tools and techniques that could help them take the required steps toward long-term, profitable customer relationships. The tools that would be beneficial in using the installed base information to an increasing extent, should also fit in the OEMs' decision-making processes and their wider context, including their customers. More specifically, there is a need for approaches that would extend OEMs' understanding about their customers' needs, behavior, and the impact of the OEMs' service activities on the profitability of the parties involved. It is not yet adequately understood how companies could choose useful ways to use extended financial information regarding services, and share such information among the relevant parties involved across their traditional business units and functions.

\subsection{Customer base analysis}

To inform our analysis of financial support to service governance in the context of manufacturing firms, we need an understanding about how existing research handles the issue more broadly. Customer relationship management (CRM) refers to all actions that companies take to enhance existing or future customer relationships to drive sales and profitability growth (Kumar 2010). CRM is a combination of people, processes, and technology (Chen and Popovich 2003). Technology comprises customer data and data processing, including what type of customer data companies should collect and how companies can turn customer data into information to support sales.

CRM can have many objectives. It can focus on the acquisition of new customers, recovering lost customers, customer retention, or cross- and up-selling (Reimer and Becker 2015). Cross-selling is the action of selling various types of products and services to existing customers to expand the customer relationship width. Up-selling 
is repeated sales of the initially purchased product in greater quantities or higher price segments to increase relationship depth (Reimer and Becker 2015).

Companies can collect a range of data about customers (Reimer and Becker 2015). In B2C marketing, customers' demographic data, such as age, gender, education, and income, give companies valuable information about their customers. In B2B marketing, the customer's key figures, such as turnover, profitability, number of employees, and industry, help companies more thoroughly understand their customers' activities and needs. Companies have a variety of methods for processing customer data and dividing customers into meaningful segments. A customer profitability analysis (CPA) allocates past revenues and costs to customers as precisely as possible. Sophisticated cost allocation methods, such as activity-based costing (ABC) (Smith and Dikolli 1995; van Raaij et al. 2003) and time-driven activitybased costing (TDABC) (Dalci et al. 2010), help allocate direct and overhead costs, such as marketing, post-sales support, and delivery costs, to customers. Based on the results of a CPA, companies can divide their customers into profitability segments and increase the current and future profitability of all customers in the company's customer portfolio (Zeithaml et al. 2001).

A CPA is a retrospective approach because it measures costs and revenues per customer during a specific accounting period in the past (Holm et al. 2012). However, a truthful allocation of costs to customers is often challenging. Moreover, past revenues and costs are not a guarantee of future profits. Customer lifetime value (CLV) is another possible basis for segmentation. CLV is the present value of the future profits from a customer. CLV is a prospective approach because it predicts future customer behavior (Holm et al. 2012). The literature covers numerous CLV models in various contexts and for different purposes (e.g., Gupta et al. 2006; Fader and Hardie 2009; Rust et al. 2011; Ferrentino et al. 2016).

Many CLV models predict the future profits from a customer with remarkable accuracy. However, the implementation of CLV models requires expertise in advanced financial analytics. In addition, quite often, simple heuristics perform at least as well as stochastic CLV models (Wübben and Wangenheim 2008; Goldstein and Gigerenzer 2009; Huang 2012). Therefore, it is not surprising that many managers use rule-of-thumb-heuristics-based decision making and customer segmentation (Persson and Ryals 2014).

An RFM analysis is a simple, easy to understand, and widely used marketing technique (Verhoef et al. 2003). An RFM analysis divides customers into segments based on three variables that describe customers' past buying behavior: (1) Recency, the most recent purchase date of a customer; (2) Frequency, the number of transactions the customer made during the period (often 1 year); and (3) Monetary value, the total or average sales attributed to the customer during the period. Customers who have done frequent high-volume transactions recently will presumably respond positively to marketing activities, so their value for the company is higher.

From the perspective of implementation, a company divides each variable (R, F, and $\mathrm{M}$ ) into a suitable number of categories, typically three or five. As an example, the customer could belong to R category 3 for time if the most recent transaction was less than 1 month ago, to R category 2 if the time since the last transaction was between 1 and 3 months ago, and to R category 1 if the customer has not been active 
during the last 3 months. Respectively, a company defines meaningful thresholds for each of the $\mathrm{F}$ and $\mathrm{M}$ categories as well. The division of the variables into three categories leads to $3^{3}=27$ customer segments. As an example, $3 \times 3 \times 3$ customers are the most important customers when looking at the three variables: these customers have made recent purchases, and their transaction frequency and monetary value are high. As another example, customers in the $1 \times 3 \times 3$ segment are past major customers: their frequency and monetary value are high, but the elapsed time from the most recent purchase is alarmingly long.

The above-described customer segmentation based on RFM variables is simple and easy to implement. Alternatively, companies can use more sophisticated analytics for customer segmentation based on their RFM values. Sequential pattern mining (SPM) segmentation helps managers identify possible changes in their customers' purchasing patterns over time (Chen et al. 2009). Also other more advanced techniques are possible. For example, Chen et al. (2012) use a k-means clustering algorithm and decision tree induction for customer segmentation based on RFM values.

\subsection{Tentative framework}

OEMs need to know quite a bit about the installed base to design and enact maintenance operations in a proper way. Regarding the product-oriented services, such as spare parts and maintenance (Ala-Risku 2009; Ulaga and Reinartz 2011), the dynamics of an OEM's installed base at their customers needs to be understood thoroughly in order for the OEM to plan and control their service activities. As synthesized by Perminova-Harikoski et al. (2015), there is a clear potential in using installed based information for service sales and service business development, but such potential has neither been sufficiently empirically confirmed nor examined. Holmström et al. (2010) conclude that manufacturing companies need visibility of their customers' operations one-step beyond (deeper than) the scope of their service offering. Therefore, to be able to provide spare parts and maintenance for customers, manufacturing company needs to know, the location, scope, and characteristics of the use of their installed base. The study by Dekker et al. (2013) indicates that information about customers' equipment can support, for example, planning for responsive spare parts logistics services. In addition to the existing service operations, increased awareness of customers' operations would support the development of new service businesses. Rabetino et al. (2017) highlights that servitization requires better customer knowledge: to determine how customers use the sold equipment, companies can collect information to understand how the installed base performs.

From the viewpoint of this article, OEMs may benefit from an extended understanding about their customers' operations. The governance of the existing product-oriented service businesses is one level of using such understanding (Malleret 2006; see also Laine et al. 2012a), i.e., supporting profitable service sales with the help of the installed base information (Perminova-Harikoski et al. 2015). On the other hand, the examination of the customer behavior regarding the maintenance service activities and other operations may provide useful insights into developing new service businesses, in more advanced service 


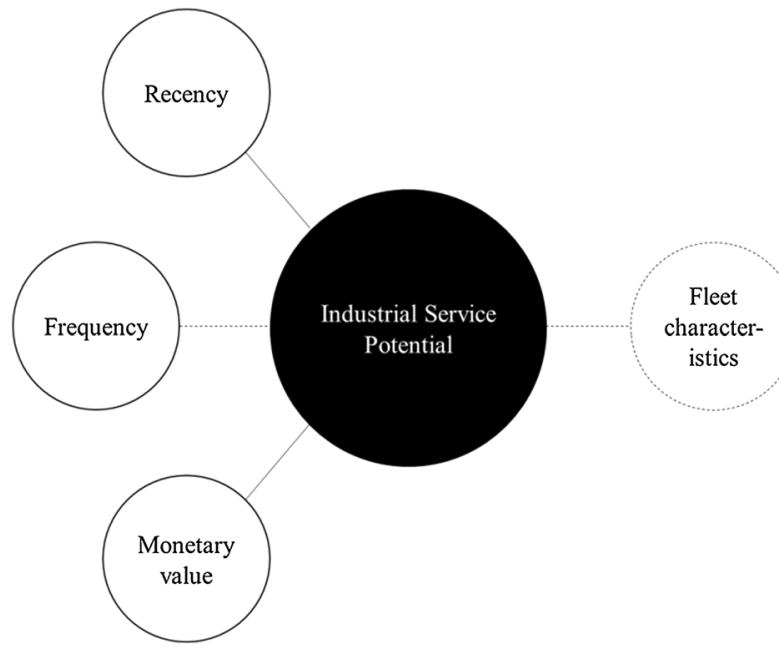

Fig. 1 The tentative framework of the RFM analysis

categories (Ala-Risku 2009; Ulaga and Reinartz 2011). This is in line with the idea of Saccani et al. (2012), who suggested the examination of the potential value of the installed base information in managing current service businesses and support the development of new, more complex service offerings. Therefore, the paper examines the potential of RFM analyses both in managing productoriented service activities and in identifying new service business opportunities. In this vein, Fig. 1 illustrates the tentative framework of the RFM analysis in this paper, where traditional RFM analyses are tentatively supplemented with fleet characteristics that could altogether reveal the customer behavior regarding product-oriented services and provide useful insights into wider service business potentials.

In Fig. 1, the traditional RFM analysis is based on $\mathrm{R}, \mathrm{F}$, and $\mathrm{M}$ variables that describe a customer's buying behavior. As the literature has recognized the potential of the installed base information in understanding the value of manufacturers' service businesses from multiple perspectives (Ala-Risku 2009; Holmström et al. 2010; Saccani et al. 2012; Laine et al. 2012b; Perminova-Harikoski et al. 2015), the tentative framework adds special variables describing the features of a particular customer's installed base and its product-oriented service consumption (Fleet characteristics) to the traditional RFM analysis. FleetCo's and ProcessCo's case studies are used next to supplement this tentative framework, and to further examine, whether the traditional RFM analysis and fleet characteristics together could reveal customers' behavior regarding the productoriented services and help OEMs identify their wider service business potential. In the following section will go into more detail regarding how the data was collected in the case studies. 


\section{Methodology}

This paper relies on two interventionist case studies (see e.g., Jönsson and Lukka 2007; Suomala et al. 2014; Laine et al. 2012b; Lyly-Yrjänäinen et al. 2017) conducted in close cooperation with globally operating machine-manufacturing companies. The two companies, FleetCo and ProcessCo were initially part of a larger project consortium in which the interventionist researchers operated. However, as the research project progressed, and mutual trust had been built among the researchers and the companies, the researchers got access to a highly unique data set. More particularly, the interventionist methodology allowed the researchers to gain access to these companies' highly classified customer data. Such data would hardly be available without the interventionist research approach that enabled the interplay between the theoretical development ('episteme') and technical development on-site ('techne') (Lyly-Yrjänäinen et al. 2017). The two companies were chosen within the local manufacturing industry, because (a) both FleetCo and ProcessCo have realized that profitability can be enhanced by adopting a customer-centric logic in after-sales operations, and (b) they wanted to develop methods and tools for customer base analysis and segmentation. Furthermore, (c) these companies granted the researchers access to their highly classified customer data. Random or theoretical sampling would hardly have resulted in such in-depth data: a manufacturing company is not likely to give their trade secrets concerning service business potential to any researcher interested. To understand the applicability of the RFM tool, it was first used in FleetCo's case to construct an understanding about whether it could provide the company with useful information, and then used for further market test in ProcessCo to validate findings from FleetCo's case (Kasanen et al. 1993).

Indeed, the interventionist approach was used because we could build access to and in-depth visibility of ongoing business development in the two companies, FleetCo and ProcessCo. Furthermore, the companies clearly needed support in their efforts to solve their real-life problems concerning customer base analysis and segmentation. The interventionist research approach suits studying the service governance practices particularly well because the transition from goods to services is a longitudinal process that requires active change agents. The interventionist approach allows researchers to take part in this longitudinal process both as participant observers and as active change agents. Therefore, the interventionist researchers can gain insight into the very core of the change process at hand, that is, the target of the intervention. This intervention can be even a very technical one, but at the same time, it may grant the interventionist researchers access to witnessing an action that links to more general management-related phenomena and hence to broader theoretical issues (Suomala et al. 2014; Lukka and Suomala 2014; Lyly-Yrjänäinen et al. 2017). To gain access to their classified data at FleetCo and ProcessCo, we were actively involved with the entire development process and used accounting-related interventions to facilitate improvements within the case companies. We could be seen as participants who were interested in developing the companies' service business, but we were free of any sort of company internal policies: 
The fact that the university was part of this [development work] and we have the scientific research aspect here. I think it shifts the communication into a neutral tone. (Analytics director, FleetCo)

The main interventions in both case studies were applications of the RFM analysis. Jönsson and Lukka (2007) highlight that it is crucial to obtain a thorough understanding of the current situation in the case company at the outset of the interventionist research process. In both case companies, we started with comprehensive financial analyses of the spare parts sales operations. In addition to actual interventions, data were collected in interviews, company data analysis, meeting facilitation, participation, and observation, and through e-mail and phone calls. The interventions sparked in-depth discussions with the company's employees and thus led to the accumulation of empirical materials. Table 1 illustrates the data collection process at FleetCo.

The implemented RFM analysis is part of a 3-year research project that began in early 2015. Before the RFM analysis, we conducted a market area analysis and created an industrial service demand forecast model. Interviewees and regular meetings were the main data collection methods. Several FleetCo employees took part in the project. However, the analytics director and the service development manager had particularly important roles in conducting the RFM analysis (Table 1).

Content-wise, the data of the analysis at FleetCo covered spare parts sales data with extensive technical details of the transactions. The analyses covered a central country, in which the number of customers was several hundreds, and the number of orders was over 100,000 during the period (2011-2015). Such extent of the data enabled a rather reliable sample of the customer behavior in this context.

Data collection at ProcessCo is illustrated in Table 2. This case study furthers a previous interventionist study in the case company that was conducted between 2015 and 2016. In the previous study, the spare parts business' profitability and market area characteristics were analyzed. As illustrated in Table 2, the data were collected through project meetings (12) and interviews (4). The main informants were the spare parts manager and spare parts experts in different market areas. In addition, the spare parts director and general manager defined the guidelines for development as the project progressed.

Regarding this case study, the project's execution was planned with the spare parts manager responsible for global sales. Following the earlier development work at ProcessCo, there was a need to examine the customer base more closely. Thus, we decided to utilize the same customer segmentation approach that was developed in the FleetCo case. As described in Table 2, a couple of meetings were held with the spare parts manager and spare parts experts to test the applicability of the outlined ideas and define the content of the information. An RFM analysis was created based on an extensive amount of spare parts sales data gathered from the company's data warehouse system. Finally, the RFM analysis was presented and reflected upon in a meeting with the spare parts director, spare parts manager, and a group of spare parts experts to gain insights into their perceptions and development ideas.

The data for the RFM analysis at ProcessCo covered spare parts sales from one selected area (2010-10/2016). The data covered slightly over a hundred customers, 


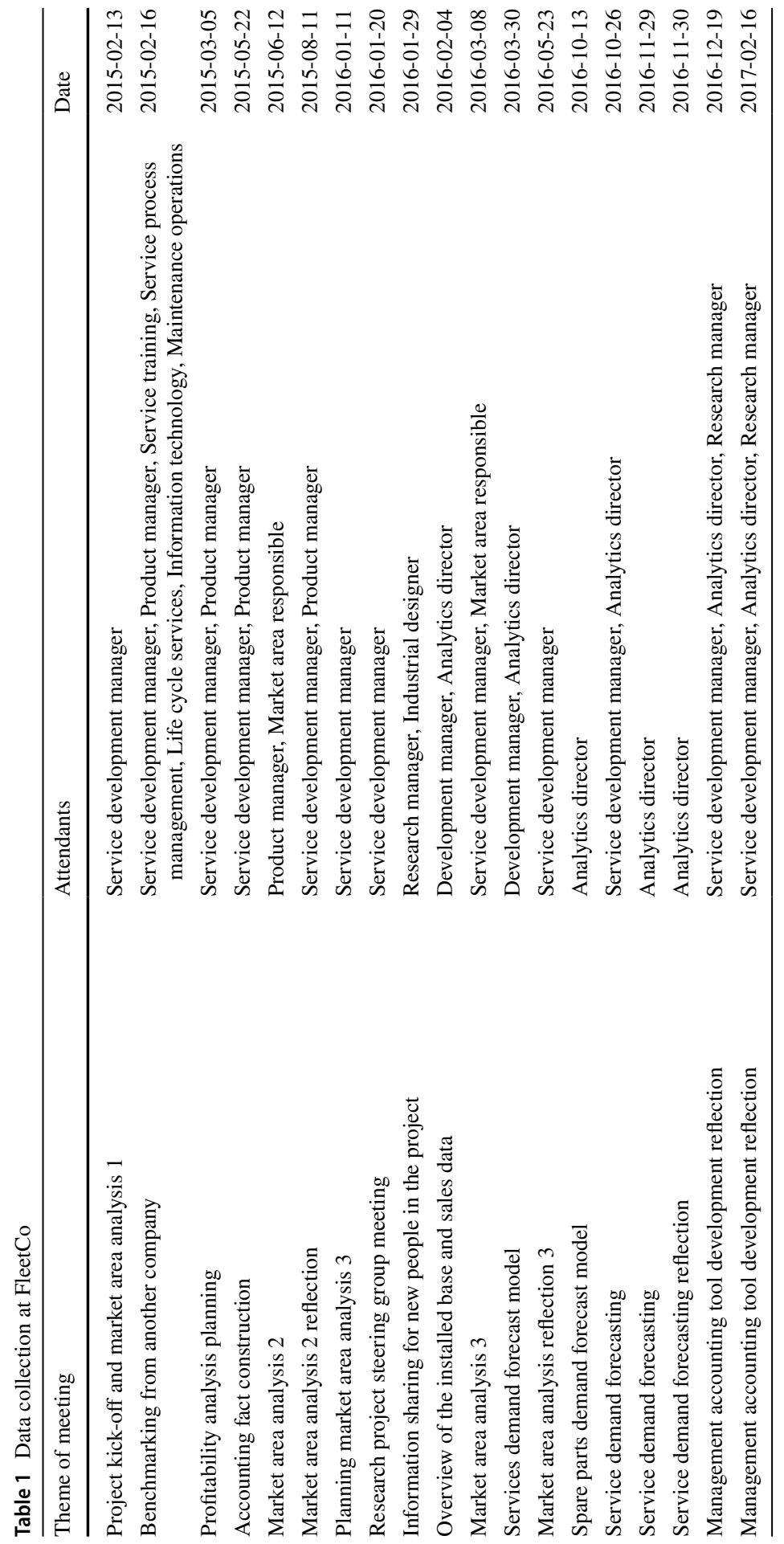




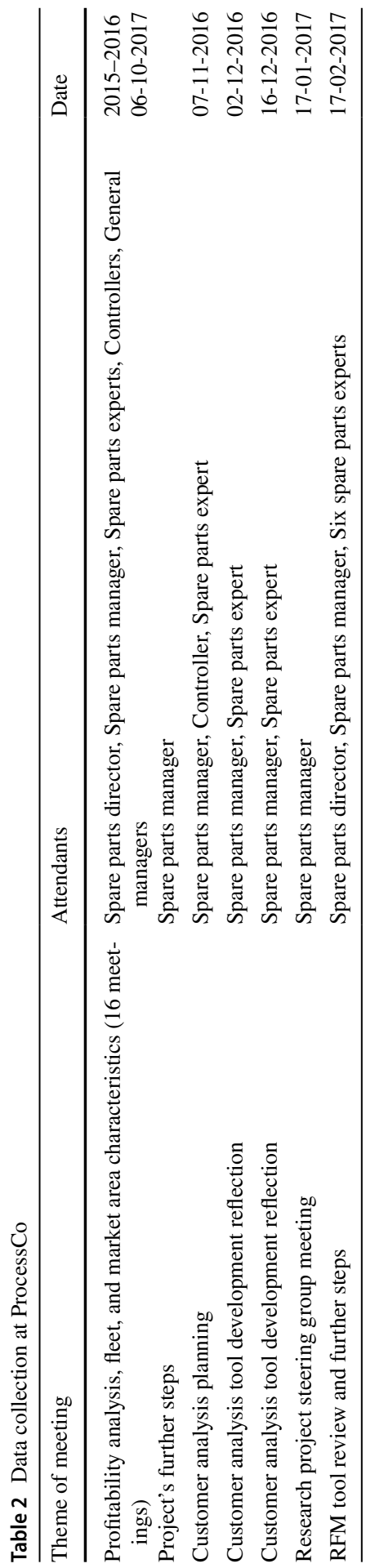


and the number of orders was over 2000. In addition to the RFM variables, the analysis included information about the pieces of machinery at ProcessCo's customers' sites. Although the technical details about the spare parts and the installed base were not as extensive as in the FleetCo analysis, also this data provide a solid starting point for a reliable RFM analysis.

\section{Empirical findings from the interventionist case studies}

\subsection{Overview of the case study environments}

FleetCo is a large industrial OEM that operates on six continents and is headquartered in Europe. FleetCo has two main capital product segments. The company provides a wide range of industrial services to its installed base and customers. These services represent more than half of FleetCo's turnover, and they encompass everything needed to keep the installed base in action: installation, spare parts, and maintenance. FleetCo has tens of thousands of different spare parts. The company divides spare parts into two main categories: spare parts and wear parts. Wear parts are spare parts that will wear evenly when the device is in use. In total, spare parts account for over a half of the company's after-sales. The company uses several distribution centers to deliver spare parts globally.

FleetCo has thousands of industrial customers around the world. In some market areas, the role of dealers is significant. Customers range in size from one-man businesses to globally operating industrial companies. FleetCo's installed base covers thousands of pieces of equipment. FleetCo segments their customers based on their geographic location and industry type. The company also has comprehensive financial reporting practices and a separate analytics department that gathers and analyses information about the sales and installed base. FleetCo's installed base database contains multiple types of relevant information about sold pieces of capital equipment: initial owner, type, installation date, mode of operation, and location. The oldest pieces of equipment still running are over 40 years old. The sales database, in turn, contains comprehensive order information: customer, sold items, the quantity of sold items, and unit price (in the case of spare parts). Based on the information, FleetCo produces reports of actual sales, prepares sales forecasts, and calculates customers' potential based on their installed base.

Overall, FleetCo's financial reporting practices serve their purpose. However, the company has identified areas for improvement. First, analytics should produce sales forecasts. In particular, forecasting the demand for spare parts is important because too large quantities of inventory runs the risk of obsolescence, whereas too little quantities of inventory runs the risk of losing sales and customers. Second, the company should identify — as soon as possible - those customers that are "lost" to competitors or are in danger of being lost. Third, analytics should recognize a customer's abnormal consumption of spare parts. Abnormality may be caused by, for example, a customer buying some spare parts from FleetCo's competitors. In addition, improper use of a piece of equipment can cause a particularly high consumption of spare parts. Identified abnormalities, in turn, could be useful selling points. 
Process Co has plenty of factories and offices around the world and is headquartered in Europe. Its business is organized around four business lines in five geographical market areas. Regarding the selected product category under study, the company is serving hundreds of customers globally, and its own installed base is a few hundred units. Most of its spare parts business comes from transactional sales. Other channels for spare parts sales are maintenance offerings and long-term service agreements. Daily spare parts activities are handled through four country/sales companies located around the world. The sales teams are quite different from each other in terms of their roles and responsibilities. This leads to, for example, internal business transactions, complicating the management control practices. The unit that manages ProcessCo's machinery sales projects also coordinates with the global spare parts sales division. Hence, they have the best technical knowledge and provide considerable sales support to the other spare parts teams.

ProcessCo's financial reporting practice does not encourage interactions between machine deliveries and service activities. According to employees, they are not accustomed to examining the financial figures of machinery and spare parts sales combined in the same report because the efforts of these functions are not centrally coordinated. On the other hand, in the company, there is no coherent installed base data available that could support the analysis of the business potential stemming from customers' equipment fleets. The sales teams are also lacking resources to collect and analyze customer data that could support the exploitation of business potential. Thus, there is a clear need to create a practical and simple tool that can increase awareness of customers and enable value-based segmentation.

FleetCo and ProcessCo are interested in where their installed base is located, how it is used, and how customers are purchasing services in proportion to their expectable service consumption. To build such understandings, FleetCo and ProcessCo need to gather installed base data on each installed piece of machinery, thus accumulating data about each customer in total, each country in total, and the whole market in total. The RFM analysis would provide direct benefits for transactional daily spare part activities, for governing those service sales. Regarding the maintenance activities and long-term service activities, understanding the spare part consumption more thoroughly among the customers would enable refining and further developing those more advanced services. This would require, however, a unified information system for the RFM analyses and understanding about different spare part channels.

\subsection{RFM analysis for FleetCo}

The research project began in early 2015 (Table 1). A comprehensive market area analysis for two countries was the first outcome (March 2015-May 2016, Table 1). After this, the next step was a statistical model that could forecast sales for industrial services. In summer 2016, the research project was at a turning point. What should we do next? How should we promote, in particular, spare parts and industrial service sales? FleetCo had recently reduced its sales resources and was interested in how it could support service sales. The analytics director had two ideas: First, the analysis should identify lost customers and customers that FleetCo was in danger of losing. 


\begin{tabular}{|c|c|c|c|c|c|c|c|}
\hline \multirow[t]{2}{*}{ Monetary value } & & \multicolumn{6}{|c|}{ Frequency } \\
\hline & & \multicolumn{2}{|l|}{ F3 } & \multicolumn{2}{|l|}{ F2 } & \multicolumn{2}{|l|}{ F1 } \\
\hline \multirow[t]{9}{*}{ Recency } & \multirow[t]{3}{*}{ R3 } & M3 & Stars & & Stars & M3 & Stars \\
\hline & & M2 & Betrayers & M2 & Betrayers & M2 & Betrayers \\
\hline & & M1 & Betrayers & M1 & New/Betrayers & M1 & New/Betrayers \\
\hline & \multirow[t]{3}{*}{ R2 } & M3 & Frustrated & M3 & Frustrated & M3 & \\
\hline & & M2 & Betrayers & M2 & Betrayers & M2 & Betrayers \\
\hline & & M1 & Betrayers & M1 & Betrayers & M1 & Betrayers \\
\hline & \multirow[t]{3}{*}{ R1 } & M3 & Lost & M3 & Lost & M3 & \\
\hline & & M2 & Lost & M2 & Lost & M2 & \\
\hline & & M1 & & M1 & & M1 & Tail \\
\hline
\end{tabular}

Fig. 2 A graphical presentation of FleetCo's service customers' segmentation using the RFM tool

Second, the analysis should identify customers who buy spare parts differently compared to other customers with a similar installed base. These customers may buy some spare parts from competitors, or they might use their installed base in an atypical way. As a concrete action, sales should immediately contact the lost customers, dig into the causes behind the sales drop, and win these customers back. Atypical spare parts consumption reveals where salespeople should focus their efforts on.

We suggested a specific "RFM analysis" as a response to this challenge at FleetCo. In contrast to sophisticated but potentially complex statistical tools, an RFM analysis is easy to understand and simple to implement. For example, recency is an indicator of the existence of the customer relationship. The longer the time since the customer's most recent purchase, the more likely the customer is lost. This is especially the case if the customer has previously purchased services on a regular basis. The RFM analysis is widely used in the B2C marketing context (Verhoef et al. 2003). Importantly, in this research project, FleetCo could apply the RFM analysis in the B2B context.

The RFM analysis was agreed upon. The data of the analysis covered spare parts sales from one central European country spanning 6 years (2011-2015). The number of customers was several hundreds, and the number of orders was over 100,000 during the period. In addition to the RFM variables, the analysis was now supplemented by three industrial services specific variables: (1) the size of customer's installed base; (2) the number of different spare parts purchased by the customer during the period (part width); and (3) the maximum amount of money spent on individual spare parts during the period (part depth). These variables would explain customers' behavior in the industrial service context.

The analysis divided each RFM variable into three categories. For example, customers who had placed orders during the last 6 months belonged to R category 3 . The customer was in R category 2 if the time since the most recent purchase was less than 1 year but over half a year. The rest of the customers belonged to $\mathrm{R}$ category 1. In total, this division resulted in 27 categories (Fig. 2). However, not every customer segment existed in the data. In addition, we combined some categories, resulting in five appropriate customer segments (see Table 3 also). 


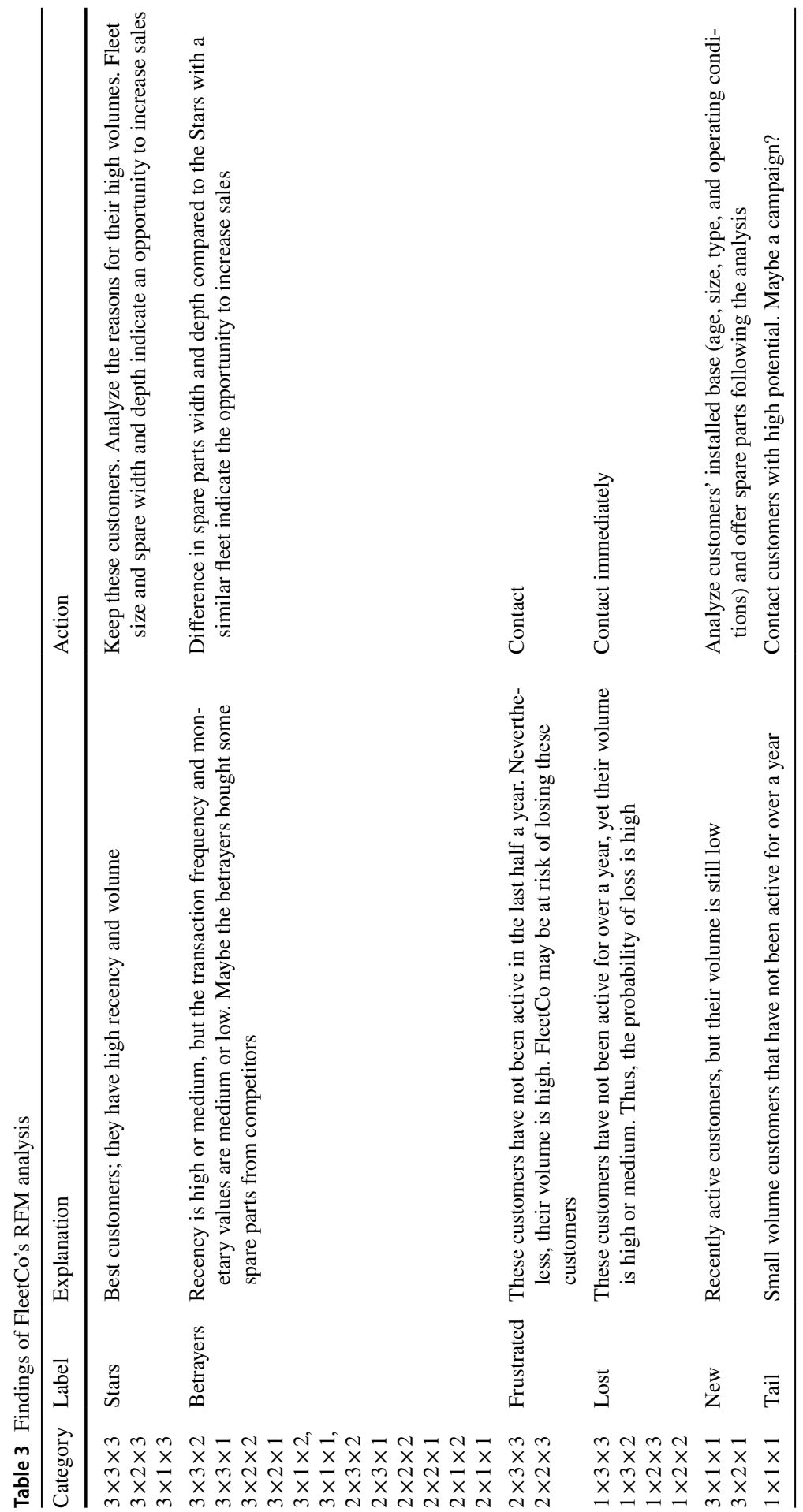


Stars are elite customers. They have bought services recently from FleetCo, they buy often, and they spend the most. In B2C marketing, frequency of purchases is important. Each customer visit to the store or online shop is an opportunity to increase sales because a customer rarely purchases only one product. However, in the product-oriented service context, a customer who makes a few big orders a year is often better than customer making several small orders. Every order requires services, such as offer preparation, order processing, and delivery. These services incur costs that OEMs do not typically bill from the customer. In addition, a few large orders are easier to manage than many small ones: maintenance operations are easier to organize, and the demand for spare parts is more predictable. Consequently, in the product-oriented service context, $3 \times 2 \times 3$ and $3 \times 1 \times 3$ customers belong to the stars category, possibly being the brightest stars.

Betrayers have recently bought services, but their volume (and frequency) is insignificant compared to their installed base. Betrayers may be purchasing some of their spare parts from a competitor. They are clearly an opportunity to increase sales, for example, an analysis of purchases may reveal which spare parts a customer buys elsewhere. Frustrated customers have recency and monetary values (and frequency) above average. However, they have not bought very recently. An OEM may be in danger of losing these customers and should contact them. Lost customers have made big purchases, usually a long time ago. An OEM should contact these customers immediately and get them back. New customers have bought services recently, but their monetary value (and frequency) is still low. An OEM should start building a relationship with these new customers. The company should give support to new customers and ensure their satisfaction. Tail customers have the lowest recency, frequency, and monetary scores. An OEM has probably lost these customers, but on the other hand, tail customers have always been small. An OEM can organize a general campaign for tail customers or even ignore them. Table 3 summarizes the findings of FleetCo's RFM analysis and provides the actions for each type of customers.

FleetCo was satisfied with the analysis and decided to test it with some simplifications. A service development manager saw that the RFM analysis together with data from a CRM system would be a usable combination at TechCo:

We took the RFM analysis and filtered it into an easily readable form: we took some extra columns away from there. So what we left were the customers who have historically ordered a wide range of spare and wear parts and are quite significant players in terms of money-both [F and $\mathrm{M}]$ were ' 3 ' but haven't ordered anything during the last half a year. [...] and also his [an area sales director's] comment was that 'of course this makes their lives easier because at the moment, what they go through in sales meetings at an annual level is which customers or accounts have been lost. [...] There's not this aspect about how widely they have ordered spare and wear parts earlier, on which rotation, etc. [...] I see this information should be incorporated into the [CRM system]. (Service development manager)

Linked to the CRM is also whether a customer who had been contacted was identified as a relevant driver for service sales potential: 
I see that visits and no-visits would make a magnificent addition to this. How can we [...] provide the sales interface with interesting data? Like 'allocate your limited resources to this or that account during the coming month at least, plus those key accounts of yours, on whose doors you're going to go knocking anyway.' No question about it, a very interesting addition. (Service development manager)

We got the customer contact activity data from the [CRM system]. [...] Calls to the customer, visits, etc. [...] Cross-referencing that data to the current version of the tool [...], that would give a direct hint about where attention has actually been paid to. (Analytics director)

The role of the transaction frequency caused debate:

How many orders - we had some problems according to which the order frequencies could locate time-wise so differently. [...] For me, this is maybe a little difficult. The customer can belong to the [frequency, F] group ' 1 ,' '2,' or '3.' But at least I don't have a clear idea about what I should think about any of these-I don't know how it would affect any of our actions. [...] Particularly with regard to frequency. To me the figure there does not matter. (Analytics director)

I wonder what kind of categorization this would result if we ditch that frequency and would replace it with the potential, the growth potential as the third aspect. That way we could see whether it's a large customer now, has it been active, and if we have potential to grow that account. (Analytics director)

Thus, in the product-oriented services context, monetary value might be more important than transaction frequency. Moreover, the long observation period of this study, 6 years, is problematic because some customer relationships started after the beginning of 2011. For these customers, the total number of transactions and volume are not comparable because the duration of the relationship has been less than 6 years. Hence, FleetCo wanted to change the method of calculating the F variable: instead of the total number of transactions, the tool showed the average number of transactions per month during the customer's activity period (the period starting from the first transaction and ending to the last transaction). After the simplifications and changes, FleetCo's sales manager tested the tool. The overall reaction was positive. He found the tool easy to use and simple to understand.

Just a practical example: we were launching a new spare part product and were wondering how we could take it to the market. We used the information about the installed base: Where is the potential installed base for this new product? This was directly communicated to the market area and we even gave a proposition that 'these and these customers seem to have suitable pieces of machinery [for this service].' In that way, [it] made life easy in the sales interface. So we gave the explanation that 'this is this kind of a product, its technical specifications' and gave a list of the customers [about] 
'these ones could be interested in purchasing this kind of service.' According to the feedback I've heard, this kind of an approach was really well accepted by the market. It really helps there. (Analytics director)

However, FleetCo identified two main challenges related to the applicability of the tool. First, the implemented analysis was a one-time report. Regularly implemented or real-time analyses would require changes in FleetCo's sales processes and information systems, including how sales efforts are prioritized:

All these kind of analyses, they require the process: how this [is] run then? How is it verified that it's used in the market area? [...] You can analyze so many things, you need to choose the objects of analysis and which processes are going to run. And how are these prioritized? (Analytics director)

Second, the problem of how to motivate staff to use the tool regularly came up. Maybe more importantly, FleetCo saw a concern about how to ensure that the results of the analysis will lead to actions and eventually increase sales and customer value:

We are not trying to question salespeople's expertise, but rather we wish to make it more efficient and bring those new tools to the everyday work to hopefully facilitate work even on the short term. [...] In one central European country, there were eight after-sales-oriented salespeople in the beginning of last year. Now there are six. Surely, the amount will not increase at least in the coming year or two. So it's acknowledged that tools are needed, there need to be skills to use them, they need to be usable. (Service development manager) The higher-level analytics is starting to be quite in a good shape, and it's ennobled already. But where I see the potential—and what perhaps is the thing for the future-is how we incorporate it [the analytics] in everyday work. Operative analytics. It's at market-level and dealer-level. (Analytics director)

The sales manager focused, in particular, on frustrated and lost customers. For each customer, he wrote down the reason for underachievement in sales. The analytics director divided these reasons into two parts: natural causes and excuses. Natural causes are causes that can immediately be accepted, such as that a customer no longer exists, the customer identification number has changed, or the customer no longer uses the installed base. Excuses, in turn, are much more ambiguous, such as that the customer has no potential. Lack of potential is a good explanation if the customer's installed base is small. However, lack of potential is not a good explanation if the customer has a significant installed base. The true reason may be that the interactions with some customers are more difficult than with others. Contact with such customers is outside the sales staff's comfort zone. An easy explanation, such as the lack of potential, provides an excuse. In all, a crucial problem was that those customers that FleetCo should have had information about, they did not; whereas they had more information about those customers they already managed to do business with.

There is this logical problem here. Those customers that we are in close contact with, to whom we sell a lot and to whom we have recently sold 
[something]. More probably we have a better picture about their installed base and how many hours per year the machines are running. Whereas on this list, we have sorted out those customers that have not gained that much attention and here the information about the installed base is in a poorer state. (Analytics director)

In February 2017, we decided that FleetCo had to be responsible for the next steps. Interventionist research and a neutral academic stance provided a premise to advance ideas within FleetCo, not actually carry them out. Next, FleetCo had to internally ensure that the analysis results were put into action. It is likely that the analysis itself would change too. However, all parties, management, analytics, and sales must be involved in the development. In the end, the RFM analysis is only technology, whereas CRM is a combination of technology, people, and processes (Chen and Popovich, 2003).

The RFM analysis had supported FleetCo's efforts in understanding and developing their service business concerning separate segments. For example, whereas large and significant customers are interesting, small customers are easily disregarded. FleetCo's analysis also revealed the potential of summing up the small customers and examining their combined potential:

It seems that we have these kind of customers [...] with 'not that high potential' and who are not... who at least don't seem to be the first ones in your mind. How many customers like these do we have? What is their combined potential? And can we do some more efficient marketing actions for these kinds of customers. Maybe that way, we get that business. (Analytics director)

At a more abstract level, the RFM analytics developed the way how FleetCo understood service business as a whole. In the end, the RFM analytics were only a tool for increased MA support for the sales interface:

You have to be careful not to [put] too much focus on the analysis itself. Like, 'now we have this RFM.' Maybe, fundamentally, this is just about sales planning and management. (Analytics director)

Altogether, FleetCo's case study shows that an RFM analysis could support the company at a segment level and at wider levels regarding how installed base information is understood as a part of service sales planning and management. Installed base information pinpointed useful segments within FleetCo's customers and provided easy-to-use decision-making tools for the sales interface, helping salespeople more efficiently focus on their work. For the back office, installed base information combined with CRM data could enable the pinpointing of customers who had potential but had possibly been contacted too seldom. However, an off-the-shelf RFM analysis, near to those applications used in the B2C business, could not satisfy FleetCo's needs. Rather, the RFM tool needed some modification to fit the B2B business context. 


\subsection{RFM analysis for ProcessCo}

The case study at ProcessCo also brought up the need to further examine the customer base of the company, similarly to the FleetCo's case. At the end of the meeting where the results of the study were reviewed, ProcessCo's spare parts director indicated that:

We need to go deeper in the customers' sales history (Spare parts director)

Therefore, the employees suggested that a tool indicating customer-specific sales would be useful. ProcessCo's employees were willing to find top customers and potentially lost customers. They also thought that it would be necessary to see whether the customers purchase small orders on a regular basis or large orders rarely. ProcessCo also hoped that the tool could enable the user to drill into customer-level data. The employees thought that this type of tool might facilitate both everyday work and the long-term management of spare parts sales in several ways. Based on the above-mentioned requests, it was natural to adapt the RFM tool initially developed for FleetCo to examine ProcessCo's customer base as well. Hence, a valuable way to validate FleetCo's findings now emerged.

At ProcessCo, as noted, the analysis focused on spare parts sales from one country/sales company over a 6-year period (2010-10/2016, Table 2). In all, the data covered slightly over a hundred customers, and the number of orders was over 2000. In addition to the RFM variables, the analysis included information about the pieces of machinery at customers' sites. However, the application of the analysis tool was a little simpler than in FleetCo's case with regard to sold spare parts and installed base data. ProcessCo's equipment are highly customized according to customer demands, and their item management is quite complex. Thus, it was not possible to consider the data concerning sold spare part items. Although there was no comprehensive installed base data available, the tool relied on the data gathered from ProcessCo's CRM. However, the problem is that when relying on CRM data, it is only possible to get the total amount of equipment per customer, but it is not known how the equipment is being used. It could be, for example, that customer has three different pieces of equipment, of which one is in regular use, the other one used as a spare device, and the oldest one used only as test equipment. Hence, to better indicate the actual business potential, the installed base data should be more informative.

The meeting for reviewing the employees' perceptions of the RFM tool revealed many potential ways to utilize the tool and pinpointed potential development targets. According to the spare parts director:

The first impression is that this is useful to us; it is not too academic. (Spare parts director)

Especially the spare parts experts responsible for daily sales activities saw the possibility of drilling into customer-level data as very important. For example, sales people could use the tool for customer prioritizing when preparing tenders. If the salespeople are in a hurry, they will likely first respond to top customers. Based on the customer-specific data, it is possible to recognize trends in purchase 
history and analyze the possible causes and effects of these changes. As in the FleetCo case, the role of transaction frequency stirred up a debate at ProcessCo as well. Indeed, the customers' pre-planned shut-down projects play a key role in ProcessCo's spare parts business, and thus, the orders are often placed cyclically. Therefore, the nature of the business transactions should be considered when analyzing the customer-specific data. ProcessCo's spare parts director gave further validation for the RFM analysis as a possible tool for ProcessCo. The director indicated that:

It could be a quarterly tool that enables to look forward...in that sense, it is a better tool as it is possible to drill into [the] customer level. (Spare parts director)

In the analysis at ProcessCo, each RFM variable was divided into three categories, and the employees suggested that the customer segments defined in the FleetCo case (Table 3) would be applicable to ProcessCo as well. In practice, the segmentation of customers into different categories may facilitate decision making at different levels and for employees in different roles. As the following quote from ProcessCo indicates, the tool can be very useful for individual salespeople:

From this [tool], you have to look at the direction on which to target the navigator... Where you should visit (Spare parts expert, team member to another team)

In turn, especially for managers responsible for global sales, the tool could provide supportive information for long-term planning. In this regard, deriving insights from the analysis of customer segments may help in orientating the local sales forces to the right customers.

It was justifiable to test the idea and applicability of the RFM tool with a certain data set, so the first version of the tool covered sales data of only one country/sales company. However, the next version of the tool was planned to cover data from all country/sales companies, and regarding this, the spare parts director highlighted that:

It is important to see the global picture. (Spare parts director)

Moreover, the main development needs identified concerned the installed base information. The input data of the tool contained several data fields from which it was possible to derive installed base information. However, none of these fields gave a perfect picture; thus, employees tried to figure out the best possible option that could be adopted into the tool. Because the equipment and spare parts sales were normally examined separately at ProcessCo, this tool could be seen as promoting the equipment-fleet-based management of spare parts sales.

In all, the RFM analysis seemed to be an applicable tool for ProcessCo as well. This was because of the simplicity, usability, and visual appearance of the RFM tool. The managers at ProcessCo already utilized the tool when they needed to estimate the target market potential and the customers' money spent on spare parts; representing a validation of the tool developed at FleetCo (cf. Kasanen 
et al. 1993). Importantly, and perhaps more visibly than at FleetCo, ProcessCo's study underlined the RFM tool's possibility of being a decision-making aid at the salesperson's level. The tool could, for example, point out the next location thata the salesperson should possibly focus his or her efforts on. Impressions of similar use could be seen at FleetCo as well, but they involved the back-office manager, who provided the salesperson with a set of interesting or abnormal customers.

\section{Discussion and conclusions}

\subsection{Overview of the contribution of the paper}

Our interventionist case studies from FleetCo and ProcessCo showed that there is indeed potential in using installed base information for OEMs' service business development (Ala-Risku 2009; Holmström et al. 2010; Saccani et al. 2012; Perminova-Harikoski et al. 2015). In particular, the refined RFM analysis, as presented and preliminarily used in the cases of this paper, responds to the need for relatively simple, yet comprehensive tools for better understanding the value generation dynamics within service activities in OEMs (as suggested also by Laine et al. 2012b). Many manufacturing companies currently desire these kinds of analyses to overcome their challenges in governing and developing their service businesses.

In a way, the salesperson wouldn't have to use time for filtering or further understanding of the data. It should be as ready-chew'd as possible. ${ }^{1}$ You could directly use it in your own work. That's one goal. (Analytics director, FleetCo)

The contribution of this paper is threefold. First, we contribute to the literature on service business development by using an RFM analysis that was adopted earlier for the B2C context: we show that an RFM analysis can be applied in the product-oriented, B2B context but needs to be supplemented with variables describing the fleet size, service type width, and service type depth. Especially, the RFM analysis may help in governing the existing, transactional services sales and prevent customer losses, but may also provide insights regarding new potential service businesses.

Second, in particular, this paper adds to the studies by Wagner and Lindemann (2008), Ala-Risku (2009), Holmström et al. (2010), Saccani et al. (2012), Dekker et al. (2013), and Rabetino et al. (2017) by showing the possible ways of using installed base information in service management. The present study adds to the literature on the governance of product-oriented services in manufacturing, particularly, by showing beneficial types of information about customers that industrial companies need to focus on to create value by acquiring larger shares of their

\footnotetext{
1 Previous literature, introduces several models for predicting the lifetime of a customer relationship. As an example, the Pareto negative binomial distribution (NBD) model predicts the probability that a customer relationship is alive (Pareto distribution) and the number of expected transactions in a given time period (Schmittlein et al. 1987; Fader and Hardie 2009). However, these models are not always easy to understand, and their implementation requires knowledge in statistics and special software.
} 
potential service business market (Oliva and Kallenberg 2003; Ala-Risku 2009; Ulaga and Reinartz 2011). This paper shows that information about fleet characteristics combined with an RFM analysis can support service sales both in the sales frontline and back office.

Third, this paper also adds to the literature on management accounting supporting service business development in manufacturing companies (Araujo and Spring 2006; Baines et al. 2009; Laine et al. 2012a, b; Korhonen et al. 2016; Lindholm et al. 2017). Particularly, we add to these studies by showing how companies could structure and utilize their installed base information for service business development. In our paper, FleetCo's case study laid the foundation for using the RFM analysis in the product-oriented service context. ProcessCo's case study offered some validation for the initial findings by showing that the RFM tool developed was seen as a potentially useful aid in managerial work in service business development and managerial work therein (cf. Hall 2010). In all, we show how the practices of accounting and business analytics can support service business development.

Next, we are going to go into more detail about each of these contributions. We will create three propositions for future research to address and revise the tentative framework of the paper.

\subsection{Our extension to the RFM analysis}

The present paper shows that OEMs could use the RFM analysis for customer segmentation regarding their product-oriented services. The analysis is useful when OEMs want to identify, for example, lost customers, customers in danger of being lost (e.g. frustrated), star customers, and potential customers (e.g. betrayers).

The present study demonstrates how OEMs can extend the traditional RFM analysis; this is an important contribution to studies that notice the relevance of installed base information for service business development (Wagner and Lindemann 2008; Holmström et al. 2010; Saccani et al. 2012; Dekker et al. 2013; Perminova-Harikoski et al. 2015; Rabetino et al. 2017). The extended analysis includes four additional variables: (1) the size of a customer's installed base; (2) the number of different services (such as spare parts) purchased by a customer during a period (service type width); (3) the maximum amount of money spent on individual types of service (such as spare parts) during a period (service type depth); and (4) the fleet service business potential altogether. In addition, the number and type of customer contacts can supplement the RFM analysis. By combining contact information and an RFM analysis, companies can evaluate the impact customer contacts have on customer potential and actual purchases. OEMs can use these additional variables for evaluating the overall customer potential and finding useful sales points. These supplementing variables lead to our first proposition.

Proposition 1 The size of the installed base, service type width, service type depth, and number of customer contacts are drivers of service business potential in the product-oriented services. 


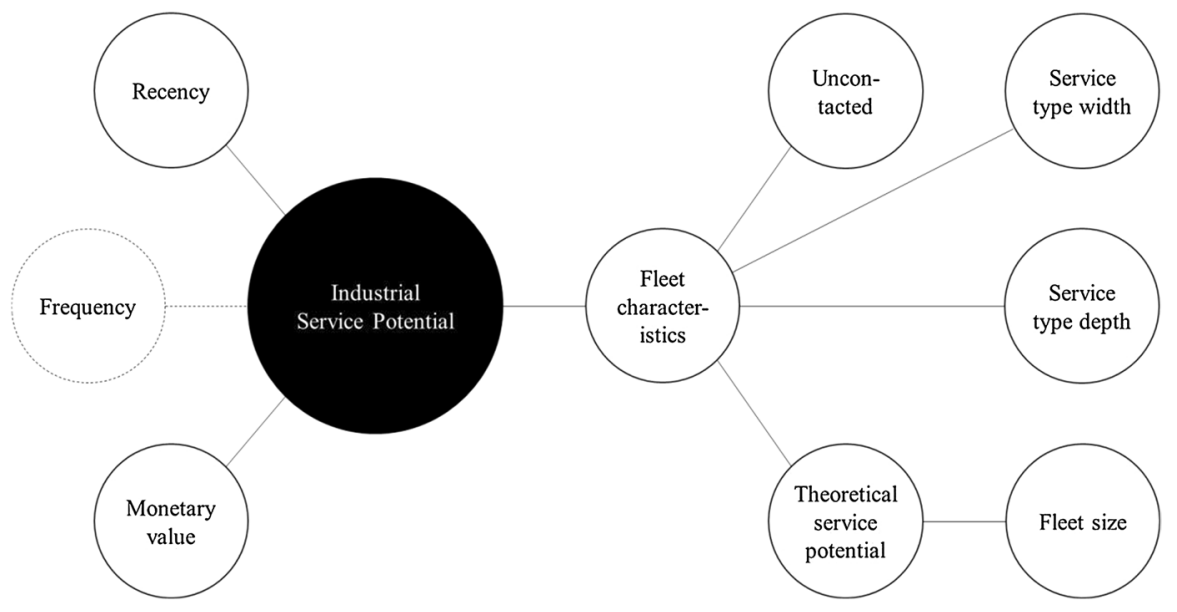

Fig. 3 Exploratory findings on the meaning of different variables in the fleet service context-a revised framework

Finally, our empirical findings enable us to revise the tentative framework of the paper, by providing more information about useful information of the fleet characteristics in this context (Fig. 3). This revised framework holds both academic and practitioner implications. Academic researchers can supplement an RFM analysis in different service management contexts using the novelties of our revised framework. Practitioners can use the revised framework to govern their service development. It is notable that in the product-oriented services context, fleet characteristics can provide useful information for decision making. However, the F in RFM, i.e. "frequency" might play a minor role in product-oriented B2B-services when compared to the $\mathrm{B} 2 \mathrm{C}$ context, as indicated by our two case studies, and discussed more particularly next.

\subsection{Our contribution to the literature on service business management}

The research reveals the differences between the business-to-business service context and the consumer business context when using the RFM analysis. The importance of the variables $\mathrm{R}, \mathrm{F}$, and $\mathrm{M}$ is not the same in the product-oriented services as in the $\mathrm{B} 2 \mathrm{C}$ marketing. Here, the role of transaction frequency is controversial; from an OEM's point of view, a customer who makes fewer large orders is cheaper to serve than a customer who makes a number of small orders (see Fig. 3 above). Thus, in product-oriented services, the customer's monetary value might be a more important indicator than transaction frequency. Indeed, our empirical findings show that the frequency variable in these service purchases might not be as relevant as in consumer business. However, our data show that the frequency variable is not irrelevant-rather, we expect its meaning to depend on the context. For example, an OEM would hardly be content if a customer placed an order every 10 years. Neither would the service provider wish that the customer place orders daily. There is a middle 
ground somewhere, depending on the context: this middle ground allows both a close customer relationship and enough room for coordinating the service operations. This finding leads to our second proposition for future research to address.

Proposition 2 The frequency variable in an RFM analysis is a less significant driver of service business potential in the product-oriented services than in the consumer business context.

Regarding the frequency variable, it is noteworthy that in the comprehensive service contracts and performance warrantees, it may be the responsibility of an OEM to take care of the spare part and maintenance activities-with a frequency that is most appropriate from the perspective of such contract. However, understanding the frequencies of the transactional, product-oriented service sales could help in understanding the dynamics of some activities within the more comprehensive contracts as well. The wider validity of the aforementioned proposition 2 is for future researchers to test. The future examination of the frequency variable could also help find even more purposeful ways to segment customers. So far, the present study identifies only six meaningful customer segments (see Fig. 2 and Table 3); the purposeful segments should also be revisited in future studies.

\subsection{Our contribution to management accounting and control supporting service operations}

Our findings relate to the literature on supporting the service transformation (Baines et al. 2009). In essence, the application of an RFM analysis modified to the productoriented service context represents an example of a tool that supports transforming OEMs' businesses towards services that support their product sales. At the same time, and as a wider implication to the management accounting and governance literature (Araujo and Spring 2006; Baines et al. 2009; Laine et al. 2012a, b; Korhonen et al. 2016; Lindholm et al. 2017), the utilization of RFM analyses requires rethinking of the units of analyses traditionally used in decision-making. This rethinking also involves various relevant parties in the decision-making and implementation ${ }^{2}$ processes to realize the potential impacts of the enhanced awareness of customersthat is governing better the existing service sales and finding new service business opportunities.

In all, our empirical findings show that service management can be supported at three distinct levels of management accounting and control. The refined RFM analysis can (a) be used at the level of a single customer case (as in deciding to which customer the salesperson is going to call next). The refined RFM analysis can (b) help identify certain specific customer segments, and hence support focused actions and campaigns, for example. Finally, the refined RFM analysis can (c) support the development of the whole service system and organization and give information about how a customer segment relates to the wider picture of service management within a company. This level of analysis connects to wider organization and responsibility 
structures in service business development. These findings lead to our third and final proposition.

Proposition 3 The RFM analysis drives service profitability consciousness when used among stakeholders together with information about the profitability of different current products and services as well as new service business opportunities.

Eventually, the profitability consciousness could lead to better business performance as well (Velasquez et al. 2015). As a managerial implication, indeed managers could benefit from combining the RFM analysis with profitability information about products, services, and customers. Such analyses could also directly support new service development, by unveiling the value generation dynamics in the existing product-oriented service activities.

\subsection{Conclusions and future research agenda}

This paper has shown a new direction for analyzing installed base information and using it for governing existing product-oriented service sales and service business development. Our interventionist case studies show that certain aspects of management accounting and control for service business development are typically situated outside normal yearly and monthly reporting - that is in business analytics that could accompany reporting.

Importantly, we have provided a refined RFM framework that can specifically be used in managing service businesses in OEMs. Further, we have made three propositions for future researchers to address. Finally, service type width and depth are concepts that are potentially transferable across different contexts: their wider plausibility is an important agenda for future researchers to address.

Acknowledgements This paper is based on the DIMECC S4 Fleet research project and the authors greatly acknowledge the financial support of the Finnish Funding Agency for Innovation. The authors wish to thank the case companies' valuable input, both in terms of research cooperation, and offering access to data collection. Moreover, the authors are grateful to the editor and anonymous reviewers for their insightful comments on the previous version of the paper.

Open Access This article is distributed under the terms of the Creative Commons Attribution 4.0 International License (http://creativecommons.org/licenses/by/4.0/), which permits unrestricted use, distribution, and reproduction in any medium, provided you give appropriate credit to the original author(s) and the source, provide a link to the Creative Commons license, and indicate if changes were made.

\section{References}

Ala-Risku, T. (2009). Installed base information: Ensuring customer value and profitability after the sale. Helsinki University of Technology, Department of Industrial Engineering and Management doctoral dissertation series, 2009/6, $191 \mathrm{p}$.

Anderson, J. C., \& Narus, J. A. (2003). Selectively pursuing more of your customer's business. Sloan Management Review, 44(3), 42-49. 
Araujo, L., \& Spring, M. (2006). Services, products, and the institutional structure of production. Industrial Marketing Management, 35(7), 797-805.

Baines, T., Lightfoot, H., Benedettini, O., \& Kay, J. (2009). The servitization of manufacturing: A review of literature and reflection on future challenges. Journal of Manufacturing Technology Management, 20(5), 547-567.

Cavalieri, S., Gaiardelli, P., \& Ierace, S. (2007). Aligning strategic profiles with operational metrics in after-sales service. International Journal of Productivity and Performance Management, 56(5), $436-455$.

Chen, D., Sain, S. L., \& Guo, K. (2012). Data mining for the online retail industry: A case study of RFM model-based customer segmentation using data mining. Journal of Database Marketing and Customer Strategy Management, 19(3), 197-208.

Chen, I. J., \& Popovich, K. (2003). Understanding customer relationship management (CRM): People, process, and technology. Business Process Management Journal, 9(5), 672-688.

Chen, Y., Kuo, M., Wu, S., \& Tang, K. (2009). Discovering recency, frequency, and monetary (RFM) sequential patterns from customers' purchasing data. Electronic Commerce Research and Applications, 8(5), 241-251.

Cinquini, L., Collini, P., Marelli, A., \& Tenucci, A. (2015). Change in the relevance of cost information and costing systems: Evidence from two Italian surveys. Journal of Management and Governance, 19(3), 557-587.

Cohen, M. A., \& Whang, S. (1997). Competing in product and service: A product life-cycle model. Management Science, 43(4), 535-545.

Dalci, I., Tanis, V., \& Kosan, L. (2010). Customer profitability analysis with time-driven activity-based costing: A case study in a hotel. International Journal of Contemporary Hospitality Management, 22(5), 609-637.

Dekker, R., Pinçe, Ç., Zuidwijk, R., \& Jalil, M. N. (2013). On the use of installed base information for spare parts logistics: A review of ideas and industry practice. International Journal of Production Economics, 143(2), 536-545.

Fader, P. S., \& Hardie, B. G. (2009). Probability models for customer-base analysis. Journal of Interactive Marketing, 23(1), 61-69.

Ferrentino, R., Cuomo, M., \& Boniello, C. (2016). On the customer lifetime value: A mathematical perspective. Computational Management Science, 13(4), 521-539.

Gebauer, H., Fleisch, E., \& Friedli, T. (2005). Overcoming the service paradox in manufacturing companies. European Management Journal, 23(1), 14-26.

Goldstein, D. G., \& Gigerenzer, G. (2009). Fast and frugal forecasting. International Journal of Forecasting, 25(4), 760-772.

Gupta, S., Hanssens, D., Hardie, B., Kahn, W., Kumar, V., Lin, N., et al. (2006). Modeling customer lifetime value. Journal of Service Research, 9(2), 139-155.

Hall, M. (2010). Accounting information and managerial work. Accounting, Organizations and Society, 35(3), 301-315.

Holm, M., Kumar, V., \& Rohde, C. (2012). Measuring customer profitability in complex environments: An interdisciplinary contingency framework. Journal of the Academy of Marketing Science, 40(3), $387-401$.

Holmström, J., Brax, S., \& Ala-Risku, T. (2010). Comparing provider-customer constellations of visibility-based service. Journal of Service Management, 21(5), 675-692.

Huang, C. (2012). To model, or not to model: Forecasting for customer prioritization. International Journal of Forecasting, 28(2), 497-506.

Jääskeläinen, A., Laihonen, H., Lönnqvist, A., Palvalin, M., Sillanpää, V., Pekkola, S., et al. (2012). A contingency approach to performance measurement in service operations. Measuring Business Excellence, 16(1), 43-52.

Jönsson, S., \& Lukka, K. (2007). There and back again: Doing interventionist research in management accounting. In C. S. Chapman, A. G. Hopwood, \& M. D. Shields (Eds.), Handbook of management accounting research (pp. 373-397). Amsterdam: Elsevier.

Kasanen, E., Lukka, K., \& Siitonen, A. (1993). The constructive approach in management accounting research. Journal of Management Accounting Research, 5, 243.

Korhonen, T., Stormi, K., Laine, T., \& Liew, A. (2016). Examining technical and behavioural possibilities in developing fleet services in the machinery manufacturing context. Proceedings of Pragmatic Constructivism, 6(1), 3-13.

Kumar, V. (2010). Customer relationship management. Hoboken: Wiley. 
Laine, T., Korhonen, T., Suomala, P., \& Rantamaa, A. (2016). Boundary subjects and boundary objects in accounting fact construction and communication. Qualitative Research in Accounting and Management, 13(3), 303-329.

Laine, T., Paranko, J., \& Suomala, P. (2012a). Management accounting roles in supporting servitisation: Implications for decision-making at multiple levels. Managing Service Quality, 22(3), 212-232.

Laine, T., Paranko, J., \& Suomala, P. (2012b). Using a business game concept to enhance servitization: A longitudinal case study. Managing Service Quality, 22(5), 428-446.

Lindholm, A., Laine, T. J., \& Suomala, P. (2017). The potential of management accounting and control in global operations-profitability-driven service business development. Journal of Service Theory and Practice, 27(2), 496-514.

Lukka, K., \& Suomala, P. (2014). Relevant interventionist research: Balancing three intellectual virtues. Accounting and Business Research, 44(2), 204-220.

Lyly-Yrjänäinen, J., Suomala, P., Laine, T., \& Mitchell, F. (2017). Interventionist management accounting research: Theory contributions with societal impact. London: Routledge.

Malleret, V. (2006). Value creation through service offers. European Management Journal, 24(1), $106-116$.

Oliva, R., \& Kallenberg, R. (2003). Managing the transition from products to services. International Journal of Service Industry Management, 14(2), 160-172.

Pekkola, S., Saunila, M., Ukko, J., \& Rantala, T. (2016). The role of performance measurement in developing industrial services. Journal of Quality in Maintenance Engineering, 22(3), 264-276.

Penttinen, E., \& Palmer, J. (2007). Improving firm positioning through enhanced offerings and buyerseller relationships. Industrial Marketing Management, 36, 552-564.

Perminova-Harikoski, O., Tiihonen, J. T., Öhman, M., Finne, M., \& Kuusela, J. (2015). Installed base information utilisation in industrial service development and operations. In M. Martinsuo, O. Perminova-Harikoski, \& T. Turunen (Eds.), Strategic change towards future industrial service business (pp. 6-21). Tampere: Tampere University of Technology, Department of Industrial Management.

Persson, A., \& Ryals, L. (2014). Making customer relationship decisions: Analytics v rules of thumb. Journal of Business Research, 67(8), 1725-1732.

Rabetino, R., Kohtamäki, M., \& Gebauer, H. (2017). Strategy map of servitization. International Journal of Production Economics, 192, 144-156.

Reimer, K., \& Becker, J. U. (2015). What customer information should companies use for customer relationship management? Practical insights from empirical research. Management Review Quarterly, 65(3), 149-182.

Rust, R. T., Kumar, V., \& Venkatesan, R. (2011). Will the frog change into a prince? Predicting future customer profitability. International Journal of Research in Marketing, 28(4), 281-294.

Saccani, N., Alghisi, A., \& Borgman, J. (2012). The value and management practices of installed base information in product-service systems. In IFIP international conference on advances in production management systems, (pp. 415-421). Berlin, Heidelberg: Springer.

Schmittlein, D. C., Morrison, D. G., \& Colombo, R. (1987). Counting your customers: Who are they and what will they do next? Management Science, 33(1), 1-24.

Smith, M., \& Dikolli, S. (1995). Customer profitability analysis: An activity-based costing approach. Managerial Auditing Journal, 10(7), 3-7.

Suomala, P., Lyly-Yrjänäinen, J., \& Lukka, K. (2014). Battlefield around interventions: A reflective analysis of conducting interventionist research in management accounting. Management Accounting Research, 25(4), 304-314.

Ulaga, W., \& Reinartz, W. J. (2011). Hybrid offerings: how manufacturing firms combine goods and services successfully. Journal of marketing, 75(6), 5-23.

van Raaij, E. M., Vernooij, M. J. A., \& van Triest, S. (2003). The implementation of customer profitability analysis: A case study. Industrial Marketing Management, 32(7), 573-583.

Velasquez, S., Suomala, P., \& Järvenpää, M. (2015). Cost consciousness: Conceptual development from a management accounting perspective. Qualitative Research in Accounting and Management, 12(1), 55-86.

Verhoef, P. C., Spring, P. N., Hoekstra, J. C., \& Leeflang, P. S. (2003). The commercial use of segmentation and predictive modeling techniques for database marketing in the Netherlands. Decision Support Systems, 34(4), 471-481.

Wagner, S., \& Lindemann, E. (2008). A case study-based analysis of spare parts management in the engineering industry. Production Planning and Control, 19(4), 397-407. 
Witell, L., \& Löfgren, M. (2013). From service for free to service for fee: business model innovation in manufacturing firms. Journal of Service Management, 24(5), 520-533.

Wübben, M., \& Wangenheim, F. V. (2008). Instant customer base analysis: Managerial heuristics often "get it right". Journal of Marketing, 72(3), 82-93.

Zeithaml, V. A., Rust, R. T., \& Lemon, K. N. (2001). The customer pyramid: Creating and serving profitable customers. California Management Review, 43(4), 118-142.

Publisher's Note Springer Nature remains neutral with regard to jurisdictional claims in published maps and institutional affiliations.

Kati Stormi holds M.Sc. in Computer Science from Tampere University of Technology and M.Sc. in Economics from University of Tampere. Currently she is a PhD Student in the Cost Management Center (CMC) at Tampere University. Her research theme is advanced financial analytics, artificial intelligence and machine learning in particular in the servitization and industrial services context. She has published her work e.g., in Journal of Service Management.

Anni Lindholm holds a Dr. (Tech.) in Industrial Management, received from Tampere University of Technology. She has previously worked for the Cost Management Center (CMC). Her research interests lie in life-cycle costing and long-term evaluation of organizations' performance. She has published her work e.g. in International Journal of Productivity and Performance Management, Public Money \& Management and Journal of Service Theory and Practice.

Teemu Laine received a Dr. (Tech.) in Industrial Engineering and Management. He completed his dissertation focusing on the infusion of services into manufacturing. He has published in high quality academic journals, such as Journal of Management and Governance, Journal of Service Management, International Journal of Project Management and Project Management Journal. Currently, he works as research team manager for the Cost Management Center (CMC) and associate professor (tenure track) at Tampere University, Finland. His current research interests include management accounting in service business and R\&D management.

Tuomas Korhonen holds a Dr. (Tech.) in Industrial Management, received from Tampere University of Technology. He works for the Cost Management Center (CMC) at Tampere University. His research interests lie in studying the potential of management accounting in managerial work, especially in research and development management and in relation to advanced analytics. He has published his work, for example, in Journal of Management and Governance, Public Money \& Management, A Philosophy of Management Accounting: A Pragmatic Constructivist Approach, Qualitative Research in Accounting and Management, Journal of Management Control, International Journal of Project Management and Project Management Journal.

\section{Affiliations}

\section{Kati Stormi $^{1}$ (D) Anni Lindholm ${ }^{1} \cdot$ Teemu Laine $^{1} \cdot$ Tuomas Korhonen $^{1}$}

Anni Lindholm

lindholm.anni@gmail.com

Teemu Laine

teemu.laine@tuni.fi

Tuomas Korhonen

tuomas.korhonen@tuni.fi

1 Cost Management Center (CMC), Tampere University, Tampere, Finland 